Trinity University

Digital Commons @ Trinity

Psychology Faculty Research

Psychology Department

$1-2012$

\title{
Age-Related Differences in Corpus Callosum Area of Capuchin Monkeys
}

Kimberley A. Phillips

Trinity University, kphilli1@trinity.edu

Chet C. Sherwood

Follow this and additional works at: https://digitalcommons.trinity.edu/psych_faculty

Part of the Psychology Commons

Publication Details

Neuroscience

\section{Repository Citation}

Phillips, K. A., \& Sherwood, C. C. (2012). Age-related differences in corpus callosum area of capuchin monkeys. Neuroscience, 202, 202-208. doi: 10.1016/j.neuroscience.2011.11.074

This Post-Print is brought to you for free and open access by the Psychology Department at Digital Commons @ Trinity. It has been accepted for inclusion in Psychology Faculty Research by an authorized administrator of Digital Commons@ Trinity. For more information, please contact jcostanz@trinity.edu. 


\title{
Age-Related Differences in Corpus Callosum Area of Capuchin Monkeys
}

\author{
Kimberley A. Phillips ${ }^{1, \#}$ and Chet C. Sherwood ${ }^{2}$ \\ ${ }^{1}$ Department of Psychology, Trinity University, One Trinity Place, San Antonio Texas, USA 78212 \\ ${ }^{2}$ Department of Anthropology, The George Washington University, 2110 G Street NW, \\ Washington DC, USA 20052
}

\section{Abstract}

Capuchin monkeys (Cebus apella) are New World primates with relatively large brains for their body size. The developmental trajectories of several brain regions - including cortical white matter, frontal lobe white matter, and basal ganglia nuclei - are similar to humans. Additionally, capuchins have independently evolved several behavioral and anatomical characteristics in common with humans and chimpanzees - including complex manipulative abilities, use of tools, and the use of precision grips - making them interesting species for studies of comparative brain morphology and organization. Here we report the first investigation into the development of the corpus callosum and its regional subdivisions in capuchins. Corpus callosum development was quantified using high-resolution structural MRI images from 39 socially reared subjects (male $\mathrm{n}=$ 22 ; female $\mathrm{n}=18$ ) ranging in age from 4 days (infancy) -20 years (middle adulthood). The total area of the corpus callosum and the subdivisions of the genu, rostral midbody, medial midbody, caudal midbody, and splenium were traced from the midsagittal section. Total corpus callosum area displayed significant differences across this time span and was best explained by quadratic growth. Sustained linear growth was observed in the subdivisions of the genu, rostral midbody, and splenium; sustained quadratic growth was seen in the subdivision of the medial midbody. Differences in growth were not detected in the subdivision of the caudal midbody. Females had a larger raw area of the total CC and of the medial midbody and caudal midbody throughout the lifespan. Our results indicate that capuchins show continued white matter development beyond adolescence in regions related to cognitive and motor development.

\section{Keywords}

brain development; Cebus; corpus callosum

\section{Introduction}

The corpus callosum (CC) is the major white matter tract in placental mammals that exchanges sensory, motor and higher-order cognitive information information between the two cerebral hemispheres. Information transfer occurs in a highly organized fashion, connecting both homotopic and heterotopic regions along a rostral-caudal gradient. The

\footnotetext{
(C) 2011 IBRO. Published by Elsevier Ltd. All rights reserved.

\#corresponding author: Telephone: 001-210-999-7102, Fax: 001-210-999-8386, Kimberley.Phillips@ Trinity.edu.
}

Publisher's Disclaimer: This is a PDF file of an unedited manuscript that has been accepted for publication. As a service to our customers we are providing this early version of the manuscript. The manuscript will undergo copyediting, typesetting, and review of the resulting proof before it is published in its final citable form. Please note that during the production process errors may be discovered which could affect the content, and all legal disclaimers that apply to the journal pertain. 
midsagittal area of the $\mathrm{CC}$ is frequently used as a sensitive marker of brain development (Clarke et al. 1989; Rajapakse et al. 1996; Pandya et al. 1971; LaMantia and Rakic 1990; Rakic and Yakovlev 1968), hemispheric lateralization (Witelson and Goldsmith 1991; Westerhausen et al. 2010), and connectivity and function (Luders et al. 2010) (Muetzel et al. 2008; Ringo et al. 1994; Wahl et al. 2007). Additionally, studies have shown a correlation between anatomical changes within the CC and certain neurological disorders (Hasan et al. 2005; Lyoo et al. 1997; Wang et al. 1992; Woodruff et al. 1995).

Several studies documenting brain development in humans have shown that the CC exhibits sustained growth through childhood and even beyond adolescence. The midsagittal area of the corpus callosum, particularly the posterior region, increases dramatically between 5 and 18 years (Giedd et al. 1999; Giedd et al. 1996a). While the area of these regions increases, the shape becomes more compact and boundaries become more distinct (Rajapakse et al. 1996). In humans, though the CC shows the most pronounced increases in size during childhood, it also continues to increase in size into early adulthood ( $\sim 32$ years) (Keshavan et al. 2002).

Understanding how nonhuman primate brain development compares to brain development of humans is important for translational research objectives. Perhaps surprisingly, quantitative data on neuroanatomical development of the corpus callosum in nonhuman primates is rather sparse, and there is a lack of information concerning early development. Chimpanzees (Pan troglodytes) show similar development of the CC as humans, with sustained growth in the total CC and subdivisions of the genu, posterior midbody, anterior midbody, isthmus and splenium occurring between 6 years and 54 years (Hopkins and Phillips 2010). Bonnet macaques (Macaca radiata) show age-related differences in CC:brain ratio across juvenile, adolescents, and adults with all subdivisions except the genu displaying this change (Pierre et al. 2008b). Rhesus monkeys (Macaca mulatta) also show significant increases in total callosal area between the ages of 10 months and 64 months (Knickmeyer et al. 2009); however growth in regional subdivisions of the CC was not reported. A recent study of development of the CC in the fetal and early postnatal period in Papio baboons (Papio hamadryas anubis) reported non-uniform increases in area. In particular, the splenium showed the most increase in midsagittal area by postnatal week 32, whereas the genu and anterior midbody showed the least midsagittal area increase by this time (Phillips and Kochunov 2011)

Comparative data on early developmental changes in the corpus callosum would enhance our understanding of the similarities and differences among species in the neural basis of behavioral development. Capuchin monkeys are New World primates that have been extensively studied for their social complexity, cognitive ability and manipulative propensities, including tool use (Fragaszy et al. 2004). Adult capuchins have a relatively large brain for their body size (Rilling and Insel 1999). The developmental trajectories of several brain regions - including cortical white matter, frontal lobe white matter, and basal ganglia nuclei - are similar to humans (Phillips et al. 2010; Phillips and Sherwood 2008). Capuchins also possess a proprioceptive cortical area 2 and a well-developed cortical area 5, which are associated with motor planning, visually guided reaching, grasping, and manipulation (Padberg et al. 2007). In this report, we extend our study of capuchin brain development to investigate age-related differences in the size of the corpus callosum and its regional subdivisions from a cross-sectional sample of 37 capuchin monkeys. 


\section{Experimental Procedures}

\subsection{Subjects}

Magnetic resonance images were collected from 37 capuchin monkeys (Cebus apella; female $n=16$, male $n=21$ ), ranging in age from 4 days to 20 years. As the study was crosssectional in design, each subject contributed one scan (data point). Data on corpus callosum area from 14 of these subjects were previously published (Phillips et al. 2007). All subjects were socially reared and were housed at the following institutions: Hiram College, Hiram $\mathrm{OH}$; The College of Wooster, Wooster, OH; and The University of Pittsburgh, Pittsburgh, PA. The MRI scanning protocol was approved by the Institutional Animal Care and Use Committee at each institution.

\subsection{Image Collection and Procedure}

In vivo high-resolution structural MRI scans were obtained from each subject at the Neuroscience Imaging Center, University of Pittsburgh, Pittsburgh, PA. Once at the facility, subjects were initially immobilized with one of two drug cocktails: a) ketamine $(7 \mathrm{mg} / \mathrm{kg}$ ) injection IM, meditomidine $(.06 \mathrm{mg} / \mathrm{kg})$ injection IM and atropine $(.05 \mathrm{mg} / \mathrm{kg})$ injection SQ, or b) ketamine $(25 \mathrm{mg} / \mathrm{kg})$ injection IM, acetylpromazine $(1 \mathrm{mg} / \mathrm{kg})$ injection IM and atropine $(.05 \mathrm{mg} / \mathrm{kg})$ injection SC. An intravenous catheter was then placed in the saphenous vein and subjects given a bolus of propofol $(2-5 \mathrm{mg} / \mathrm{kg}$ ). A constant intravenous drip (250 $-350 \mu \mathrm{g} / \mathrm{kg} / \mathrm{min}$ ) maintained anaesthesia. Subjects were then placed into the scanner chamber and their heads were fitted inside a $16 \mathrm{~cm}$ or $12 \mathrm{~cm}$ head coil. Subjects remained anaesthetized throughout the MRI procedure and respiration rate, heart rate, and oxygen consumption were continually monitored. At the cessation of the scan, subjects receiving drug cocktail "a" received atipamazole $(0.06 \mathrm{mg} / \mathrm{kg})$ injection IM. Scan duration was approximately 60 minutes.

Subjects were scanned on the same Siemens Allegra 3.0 Tesla scanner located at the Neuroscience Imaging Center. T1-weighted images were collected using a 3D gradient echo sequence (pulse repetition $=2300 \mathrm{~ms}$, echo time $=4.4 \mathrm{~ms}$, number of signals averaged $=3$, matrix size $=320 \times 320$ ).

\subsection{Image Quantification Method}

Prior to morphometric analysis, data were converted into the ANALYZE 3D volume file format to facilitate re-slicing into orthogonal planes. Computer files for individual subjects were numerically coded prior to measurement to prevent observer bias. Each individual brain was realigned along the AC-PC and interhemispheric fissure. CC area measurements were performed by manual tracing on the midsagittal section according to the methodology originally described by Biegon et al. (Biegon et al. 1994) and later adapted to nonhuman primates by Sanchez et al. (Sanchez et al. 1998). In the Biegon et al. method, the anterior $20 \%$ of the CC was defined as the genu, the posterior $20 \%$ defined as the splenium, and the middle $60 \%$ defined as body. To adapt this to nonhuman primates, Sanchez et al. (1998), Phillips et al. (Phillips et al. 2007), and Pierre et al. (2008) further delineated the middle $60 \%$ into three equal sections: anterior midbody, medial midbody and caudal midbody. These subdivisions of the $\mathrm{CC}$ are believed to be based on differences in microstructure and functional connectivity with cortical areas (Aboitiz et al. 1992; Alexander et al. 2007; Hofer and Frahm 2006). The anterior region of the genu connects primarily higher-order cognitive regions of the frontal lobe; the anterior, medial and caudal midbody connect primarily sensorimotor regions; the posterior region of the splenium integrates visuospatial regions of the parietal, temporal, and occipital cortex. ANALYZE 10.0, an MRI analysis software program distributed by the Mayo Clinic, was used to divide and measure the corpus callosum. To subdivide the $\mathrm{CC}$, the entire length of the $\mathrm{CC}$ was first manually traced, and 
then divided into five equally spaced sections (see Figure 1) to determine area (in $\mathrm{mm}^{2}$ ). The area of each individual subdivision was summed to derive an area measure for the total CC.

\subsection{Data analysis}

We analyzed growth of the $\mathrm{CC}$ using both the raw area measures of the total $\mathrm{CC}$ and its subdivisions, and the size of the total $\mathrm{CC}$ and its subdivisions after adjusting for brain size. To statistically adjust the $\mathrm{CC}$ data for total brain volume, we followed a recommendation by Smith (2005) wherein the square root of the CC area was divided by the cube root of total brain volume for each individual to bring all measures into the same geometric dimensionality. Additionally, we applied this adjustment to the various subdivisions of the CC. Analyses of total CC and CC subdivision areas were conducted using ANCOVA to determine the effects of sex and age. We used a series of ANCOVAs for several reasons. First, we wished to avoid the problem of multicollinearity on the total CC area (as total CC is a linear combination of the five CC subdivisions). Secondly, as testosterone modulates regional callosal architecture during development, differentially influencing subdivisions (Moffat et al. 1997), we conducted separate analyses on each raw subdivision measure. Age was treated as a fixed factor in these analyses, categorizing subjects as either "young" $(\leq 3$ years) or "adult" ( $>3$ years) based upon the age at which maximum total brain volume is attained (Phillips and Sherwood 2008). F- tests were then used to determine whether linear or quadratic growth models best fit the developmental change in these regions (Hasan et al. 2008; Phillips and Sherwood 2008; Pujol et al. 1993; Rauch and Jinkins 1994). SPSS 18.0 was used for conducting all analyses.

\section{Results}

\subsection{Raw area CC measures}

The raw area of the total $\mathrm{CC}$ was significantly influenced by sex. Females had a larger raw area of the total CC than males $\left(F(1,33)=4.96, p=.033\right.$, partial $\eta^{2}=.13$; Figure 2a). The subdivision of the caudal midbody was significantly influenced by sex, with females having larger raw area than males (caudal midbody: $F(1,33)=6.87, p=.013$, partial $\eta^{2}=.17$ ). The medial midbody was significantly influenced by age (medial midbody: $F(1,33)=5.23, p$ $=.029$, partial $\eta^{2}=.14$ ), with adults having a larger raw area than young animals. There was no significant interaction of sex and age for any callosal subdivision (Figure 2b).

Total corpus callosum area displayed significant differences across this time span and was best explained by quadratic growth $\left(F(2,36)=3.89, p=0.029 ; R^{2}=.18\right.$; see Figure 3$)$. Sustained linear growth was observed in the subdivisions of the genu, rostral midbody, and splenium (genu: $F(1,37)=4.30, p=0.045 ; R^{2}=.10$; rostral midbody: $F(1,37)=5.55, p=$ $0.024 ; R^{2}=.13$; splenium: $\left.F(1,37)=3.63, p=0.065 ; R^{2}=.18\right)$. Sustained quadratic growth was seen in the subdivision of the medial midbody $\left(F(2,36)=5.90, p=0.006 ; R^{2}=.25\right)$. Differences in growth were not detected in the subdivision of the caudal midbody. Growth data for all subdivisions of the corpus callosum are displayed in Figures $4 a-3 e$.

We conducted an outlier analysis and found that the data point 0,20 was a definite outlier at $>3 \mathrm{SD}$ below the mean CC. We reran the analysis to determine the best equation to explain changes in total $\mathrm{CC}$ area across age. Excluding this data point, the relationship remained best explained by quadratic growth. The data point at 0,36 was marginal with respect to whether it could be considered an outlier (at 2.29 SD below the mean). Nonetheless, an analysis was conducted excluding both these cases. With the removal of these two subjects, the amount of variance accounted for in the relationship between total CC area and age remained best explained by a quadratic equation but was not significant $[F(2,33)=2.84, p$ 
$\left.=.073, R^{2}=.15\right]$. The linear equation was significant $\left[F(1,34)=4.64, p=.038, R^{2}=.12\right]$

but accounted for less variance in the relationship.

\section{$3.2 \mathrm{CC}$ relative area measures}

Sex and age were significant factors influencing the CC:brain ratio. Females had a larger CC:brain ratio than males $\left(F(1,33)=11.99, p=.002\right.$, partial $\left.\eta^{2}=.27\right)$; adults had a larger $\mathrm{CC}$ :brain ratio than young animals $\left(F(1,33)=7.16, p=.011\right.$, partial $\left.\eta^{2}=.18\right)$. All subdivisions - the genu, rostral midbody, medial midbody, caudal midbody, and splenium showed significant sex differences (genu: $F(1,33)=5.50, p=.025$, partial $\eta^{2}=.14$; rostral midbody: $F(1,33)=9.03, p=.005$, partial $\eta^{2}=.22$; medial midbody: $F(1,33)=9.52, p=$. 004 , partial $\eta^{2}=.22$; caudal midbody: $F(1,33)=13.46, p=.001$, partial $\eta^{2}=.29$; splenium: $F(1,33)=5.72, p=.023$, partial $\left.\eta^{2}=.15\right)$. In all cases females had larger ratios of the CC subdivision than males.

The subdivisions of the rostral midbody, medial midbody and splenium were influenced by age (rostral midbody: $F(1,33)=4.43, p=.043$, partial $\eta^{2}=.12$; medial midbody: $F(1,33)$ $=8.06, p=.008$, partial $\eta^{2}=.20$; splenium: $F(1,33)=6.85, p=.013$, partial $\left.\eta^{2}=.17\right)$. Adult had larger ratios of the $\mathrm{CC}$ subdivision than young animals.

\section{Discussion}

Capuchins showed age-related change in the area of the total $\mathrm{CC}$ and in all subdivisions except the caudal midbody. Importantly, the areas of the genu and splenium displayed agerelated change over the lifespan investigated in this sample. These regions of the CC connect areas of higher cognitive functioning and visuospatial processing, respectively. Capuchins display similarity in the development of these callosal subdivisions to humans and chimpanzees, where these regions also continue to mature well into adulthood (Hopkins and Phillips 2010; Hasan et al. 2008). Capuchins reach sexual maturity at 5 years; these data indicate continued development of the corpus callosum past adolescence. Other brain regions also show continued development past sexual maturity in capuchins, including cortical white matter, frontal lobe white matter, and basal ganglia nuclei (Phillips and Sherwood 2008; Phillips et al. 2010). Interestingly, a recent study of CC age-related changes in bonnet macaques did not report developmental changes in the genu (Pierre et al. 2008a).

Sex differences in the raw area measures were found in this sample, with female capuchins having larger raw total CC area than males, and a larger medial midbody and caudal midbody throughout the lifespan. This result, using a larger data set, is consistent with our previous work reporting sexual dimorphism of the total cross-sectional area of the CC in capuchin monkeys (Phillips et al. 2007; Phillips and Sherwood 2008) and in chimpanzees (Phillips et al. 2009) but not bonnet macaques (Pierre et al. 2008b). Previously, we have also reported significant associations between CC morphology, sex and handedness (Phillips et al. 2007), with left-handed individuals having a larger relative overall CC area than righthanded individuals. Callosal relationships to hand preference were not analyzed in the present study as we did not have handedness data on most of these additional subjects. Such additional data to further verify such relationships in capuchins are needed.

We did not detect sex differences in the growth curves of the $\mathrm{CC}$ in capuchins. Chimpanzees display sex differences in the development of the $\mathrm{CC}$, in total $\mathrm{CC}$ area and in the subdivisions of the anterior midbody, posterior midbody and isthmus (Hopkins and Phillips 2010). Whether or not sex differences are present in the development of the human CC is controversial, as reports are inconsistent (Allen et al. 1991; Giedd et al. 1996a; Giedd et al. 1996b; Giedd et al. 1999; Rajapakse et al. 1996; Lenroot et al. 2007; Hasan et al. 2008). However, different methodologies, including varying sample sizes, ages, and means of 
quantifying the CC, may explain these discrepancies. In fact, when controlling for these variables, human males and females display significant differences in the maturation of the CC and CC subdivisions (Luders et al. 2010). These sex differences vary as a function of callosal region and developmental stage. Postnatal structural changes in the human CC are likely due to myelination, pruning, and axonal redirection (Galaburda et al. 1990; Luo and O'Leary 2005).

While the use of MRI to document patterns of global developmental changes in neural structures can illustrate important patterns, such as those reported here, studies of the development of cortical microstructure will provide addition information about agedependent changes in neuronal morphology, myelination, synapse density, and the expression of signaling molecules and receptor subunits. For example, the temporal profile of the maturation of pyramidal neurons in marmoset visual cortex and dorsolateral cortex has been studied extensively (Burman et al. 2007; Bourne and Rosa 2006) using immunohistochemistry against non-phosphorylated neurofilament protein. These researchers demonstrated that pyramidal neurons in the caudal portion of the frontal lobe matures at a slower rate than the visual areas. Specifically, pyramidal neuron maturation occurred earlier in the somatosensory and motor areas, progressing rostrally in the prefrontal cortex.

Although the corpus callosum is the largest commissural tract in placental mammals, the anterior and posterior commissures also provide interhemispheric connectivity. While it was not possible to provide accurate data on age-related changes of either the anterior or posterior commissure in the present study due to limitations of voxel size of the MRI scans, such data would likely provide important details relevant to understanding brain evolution in primates. For example, in owl monkeys and marmosets the connections of the rostrotemporal auditory area pass almost exclusively through the anterior commissure (Fitzpatrick and Imig 1980; Reser et al. 2009).

Humans show pronounced postnatal growth of the $\mathrm{CC}$ in the anterior and posterior regions; the growth is age-related and occurs in a rostrocaudal wave (Thompson et al. 2000). Earlier development shows more pronounced growth in anterior regions whereas later growth is more pronounced in the posterior regions (Luders et al. 2010; Giedd et al. 1999; Giedd et al. 1996a; Rajapakse et al. 1996; Brun et al. 2008). The maturation observed in regions of the CC parallels the growth in percentage of white matter (Hasan et al. 2008; Sowell et al. 2003). Additionally, there is an increasing accumulation of data supporting the hypothesis that maturation of white matter (and subcortical brain structures) is related to the development of cognitive and motor abilities in children (Pangelinan et al. 2011). Increases in total white matter volume, including increases in volume of tracts of the corpus $\mathrm{CC}$, due to myelination improve the speed and synchronization of neural transmission - two key features in cognitive and motor development (Paus et al. 1999; Tirapu-Ustarroz et al. 2011). Cognitive and motor skills may be fundamentally interrelated. Thus, the development of the $\mathrm{CC}$ in capuchins is likely correlated with the emergence of species-specific skills and behavior. Although studies of integrated relationship between brain development, cognitive ability and motor ability in capuchins are still needed, behavioral data suggest that such coordination may occur. For young capuchins, developing the skilled manipulative actions required for becoming a proficient forager may be one of the most demanding and important challenges. Young foragers are rather inefficient and unskilled, yet persistent in their manipulation of objects. It takes up to at least 3 years for a young capuchin to develop the cognitive and motor skills used in processing food efficiently - including precision handling and tool use (Fragaszy et al. 2004). An example of how growth in the tracts of the CC might be associated with the development of skilled foraging concerns the complex foraging skill of prey capture. The increase in posterior region of the $\mathrm{CC}$, the splenium, which connects information between parietal and temporal lobes and is associated with visuospatial skills, 
may be linked to skills such as prey capture (Hellner-Burris et al. 2010), Phillips, unpublished results). Ongoing longitudinal research in our laboratory is exploring these questions, and has the potential to provide a more accurate means of tracking the development of the $\mathrm{CC}$ in capuchins and integrating brain development with development of cognitive and motor abilities.

In summary, we found that capuchin monkeys are similar to humans and chimpanzees in displaying growth in the anterior and posterior regions of the $\mathrm{CC}$ from birth through adulthood. Combined with previous data showing that capuchins display similar developmental trajectories to humans for the volume of the cortical white matter, frontal lobe white matter, and basal ganglia nuclei (Phillips and Sherwood 2008; Phillips et al. 2010), our results are likely to have significant translational implications. Identifying appropriate primate species that model the typical developmental trajectory of the human brain is an essential step before determining the mechanisms by which this course is altered in neurodevelopmental disorders.

\section{Acknowledgments}

We are grateful to Dr. Peter Strick for providing some of the MR images and for comments on an earlier draft of this manuscript; Dr. Claudia Thompson for allowing us to acquire MR images from her capuchins; our veterinary staff for their care of the animals during scanning; and the staff of the Neuroscience Imaging Center.

\section{List of the Abbreviations}

$\begin{array}{ll}\text { CC } & \text { corpus callosum } \\ \text { MRI } & \text { magnetic resonance imaging } \\ \text { IM } & \text { intramuscular } \\ \text { SC } & \text { subcutaneous } \\ \text { ANCOVA } & \text { analysis of covariance }\end{array}$

\section{References}

Aboitiz F, Scheibel AB, Fisher RS, Zaidel E. Fiber composition of the human corpus callosum. 1992:143-153.

Alexander AL, Lee JE, Lazar M, Boudos R, Dubray MB, Oakes TR, Miller JN, Lu J, Jeong E-K, McMahon WM, Bigler ED, Lainhart JE. Diffusion tensor imaging of the corpus callosum in autism. NeuroImage. 2007; 34:61-73. [PubMed: 17023185]

Allen LS, Richey MF, Chai YM, Gorskiu RA. Sex differences in the corpus callosum of the living human being. Journal of Neuroscience. 1991; 11:933-942. [PubMed: 2010816]

Biegon A, Eberling JL, Richardson BC, Roos MS, Wong STS, Reed BR, Jagust WJ. Human corpus callosum in aging and alzheimer's disease: A magnetic resonance imaging study. Neurobiology of Aging. 1994; 15 (4):393-397. [PubMed: 7969715]

Bourne JA, Rosa MGP. Hierarchial development of the primate visual cortex, as revealed by neurofilament immunostaining: Early maturation of the middle temporal area $(\mathrm{mt})$. Cereb Cortex. 2006; 16:405-414. [PubMed: 15944371]

Brun C, Lepore N, Pennec X, Chou YY, Lee AD, Barysheva M, de Zubicaray G, Meredith M, McMahon K, Wright MJ, Toga AW, Thompson PM. A tensor-based morphometry study of genetic influences on brain structure using a new fluid registration method. Med Image Comput Comput Assist Interv Int Conf Med Image Comput Comput Assist Interv. 2008; 11 (Pt 2):914-921.

Burman KJ, Lui LL, Rosa MGP, Bourne JA. Development of non-phosphorylated neurofilament protein expression in neurones of the new world monkey dorsolateral frontal cortex. European Journal of Neuroscience. 2007; 25:1767-1779. [PubMed: 17432964] 
Clarke S, Kraftsik R, Ven der Loos H, Innocenti G. Forms and measures of the adult and developing corpus callosum: Is there sexual dimorphism? Journal of Comparative Neurology. 1989; 280:213230. [PubMed: 2925893]

Fitzpatrick KA, Imig TJ. Auditory cortico-cortical projections in the owl monkey. Journal of Comparative Neurology. 1980; 192:589-610. [PubMed: 7419746]

Fragaszy, DM.; Visalberghi, E.; Fedigan, LM. The complete capuchin. Cambridge University Press; Cambridge: 2004.

Galaburda A, Rosen GD, Sherman GF. Individual variability in cortical organization: Its relationship to brain laterality and implications to function. Neuropsychologia. 1990; 28:529-546. [PubMed: 2203994]

Giedd JN, Blumenthal J, Jeffries NO, Rajapakse JC, Vaituzis AC, Liu H, Berry YC, Tobin M, Nelson J, Castellanos FX. Development of the human corpus callosum during childhood and adolescence: A longituginal mri study. Prog Neuropsychopharmacol Biol Psychiatry. 1999; 23 (4):571-588. [PubMed: 10390717]

Giedd JN, Rumsey JM, Castellanos FX, Rajapakse JC, Kaysen D, Vaitizus AC, Vauss YC, Hamburger $\mathrm{SD}$, Rapoport JL. A quantitative mri study of the corpus callosum in children and adolescents. Brain Research and Development Brain Research. 1996a; 91:274-280.

Giedd JN, Snell JW, Lange N, Rajapakse JC, Casey BJ, Kozuch PL, Vaituzis AC, Vauss YC, Hamburger SD, Kaysen D, Rapopoer JL. Quantitative magnetic resonance imaging of human brain development: Ages 4-18. Cerebral Cortex. 1996b; 6:551-560. [PubMed: 8670681]

Hasan KM, Gupta RK, Santos RM, Wolinsky JS, Narayana PA. Diffusion tensor fractional anisotropy of the normal-appearing seven segments of the corpus callosum in healthy adults and relapsingremitting multiple sclerosis patients. Journal of Magnetic Resonance Imaging. 2005; 21:735-743. [PubMed: 15906348]

Hasan KM, Kamali A, Kramer LA, Papnicolaou AC, Fletcher JM, Ewing-Cobbs L. Diffusion tensor quantification of the human midsagittal corpus callosum subdivisions across the lifespan. Brain Research. 2008; 1227:52-67. [PubMed: 18598682]

Hellner-Burris K, Sobieski CA, Gilbert VR, Phillips KA. Prey capture efficiency in brown capuchin monkeys (cebus apella) is influenced by sex and corpus callosum morphology. American Journal of Primatology. 2010; 72:502-508. [PubMed: 20077465]

Hofer S, Frahm J. Topography of the human corpus callosum revisited - comprehensive fiber tractography using diffusion tensor magnetic resonance imaging. NeuroImage. 2006; 32:989-994. [PubMed: 16854598]

Hopkins WD, Phillips KA. Cross-sectional analysis of the association between age and corpus callosum size in chimpanzees (pan troglodytes). Developmental Psychobiology. 2010; 52 (2):133141. [PubMed: 20091760]

Keshavan MS, Diwadkar VA, DeBellis M, Dick E, Kotwal R, Rosenberg DR, Sweeney JA, Minshew N, Pettegrew JW. Development of the corpus callosum in childhood, adolescence and early adulthood. Life Sci. 2002; 8 (70):1909-1922. [PubMed: 12005176]

Knickmeyer RC, Styner M, Short SJ, Lubach GR, Kang C, Hamer R, Coe CL, Gilmore JH. Maturational trajectories of cortical brain development through the pubertal transition: Unique species and sex differences in the monkey revealed through structural magnetic resonance imaging. Cereb Cortex:bhp166. 200910.1093/cercor/bhp166

LaMantia AS, Rakic P. Axon overproduction and elimination in the corpus callosum of the developing rhesus monkey. Journal of Neuroscience. 1990; 10:2156-2175. [PubMed: 2376772]

Lenroot RK, Gogtay N, Greenstein DK, Wells EM, Wallace GL, Clasen LS, Blumenthal JD, Lerch J, Zijdenbos AP, Evans AC, Thompson PM, Giedd JN. Sexual dimorphism of brain developmental trajectories during childhood and adolescence. NeuroImage. 2007; 36:1065-1073. [PubMed: 17513132]

Luders E, Thompson PM, Toga AW. The development of the corpus callosum in the healthy human brain. The Journal of Neuroscience. 2010; 30 (33):10985-10990. [PubMed: 20720105]

Luo L, O'Leary DD. Axon retraction and degeneration in development and disease. Annual Review of Neuroscience. 2005; 28:127-156. 
Lyoo IK, Lee CK, Renshaw PF. Regional atrophy of the corpus callosum in subjects with alzheimer's disease and multi-infarct dementia. Psychiatry Research. 1997; 74:63-72. [PubMed: 9204509]

Moffat SD, Hampson E, Wickett JC, Vernon PA, Lee DH. Testosterone is correlated with regional morphology of the human corpus callosum. Brain Research. 1997; 767:297-304. [PubMed: 9367261]

Muetzel RL, Collins PF, Mueller BA, Schissel AM, Lim KO, Luciana M. The development of corpus callosum microstructure and associations with bimanual task performance in healthy adolescents. Neuroimage. 2008; 39:1918-1925. [PubMed: 18060810]

Padberg J, Franca JG, DCooke DF, Soares JGM, Rosa MGP, Fiorani M Jr, Gattass R, Krubitzer L. Parallel evolution of cortical areas involved in skilled hand use. J Neurosci. 2007; 27:1010610115. [PubMed: 17881517]

Pandya DN, Karol EA, Heilbronn D. The topographical distribution of interhemispheric projections in the corpus callosum of the rhesus monkey. Brain Research. 1971; 32:31-43. [PubMed: 5000193]

Pangelinan MM, Zhang G, VanMeter JW, Clark JE, Hatfield BD, Haufler AJ. Beyong age and gender: Relationships between cortical and subcortical brain volume and cognitive-motor abilities in school-age children. Neuroimage. 2011; 54:3093-3100. [PubMed: 21078402]

Paus T, Zijdenbos A, Worsley K, Collins DL, Blumenthal J, Giedd JN, Rapoport JL, Evans AC. Structural maturation of neural pathways in children and adolescents: In vivo study. Science. 1999; 283:1908-1911. [PubMed: 10082463]

Phillips KA, Kapfenberger N, Hopkins WD. A comparative study of corpus callosum morphology and intensity in capuchin monkeys (cebus apella) and chimpanzees (pan troglodytes). Neuroscience. 2009; 159:1119-1125.10.1016/j.neuroscience.2009.01.061 [PubMed: 19356692]

Phillips KA, Kochunov P. Tracking development of the corpus callosum in fetal and early postnatal baboons using magnetic resonance imaging. The Open NeuroImaging Journal. 2011; 5 (SupplM6):181-187.

Phillips KA, Sherwood CC. Cortical development in brown capuchin monkeys: A structural mri study. NeuroImage. 2008; 43:657-664. [PubMed: 18805494]

Phillips KA, Sherwood CC, Lilak AL. Corpus callosum morphology in capuchin monkeys is influenced by sex and handendess. PLosONE. 2007; 2 (8):1-7.

Phillips KA, Sobieski CA, Gilbert VR, Chiappini-Williamson C, Sherwood CC, Strick PL. Development of the basal ganglia in capuchin monkeys (cebus apella). Brain Research. 2010

Pierre PJ, Hopkins WD, Taglialatela JP, Lees CJ, Bennett AJ. Age-related neuroanatomical differences from the juvenile period to adulthood in mother-reared macaques (macaca radiata). Brain Research. 2008a; 1226:56-60. [PubMed: 18619575]

Pierre PJ, Hopkins WD, Taglialatela JP, Lees CJ, Bennett AJ. Age-related neuroanatomical differences from the juvenile period to adulthood in mother-reared macaques (macaca radiata). Brain Research. 2008b; 126:56-60.

Pujol J, Vendrell P, Junque C, Marti-Vilalta JL, Capdevila A. When does human brain development end? Evidence of corpus callosum growth up to adulthood. Annals of Neurology. 1993; 34:71-75. [PubMed: 8517683]

Rajapakse JC, Giedd JN, Rumsey JM, Vaituzis AC, Hamburger SD, Rapoport JL. Regional mri measurements of the corpus callosum: A methodological and developmental study. Brain Development. 1996; 18 (5):379-388. [PubMed: 8891233]

Rakic P, Yakovlev PI. Development of the corpus callosum and cavum septi in man. Journal of Comparative Neurology. 1968; 132:45-72. [PubMed: 5293999]

Rauch RA, Jinkins JR. Analysis of cross-sectional area measurements of the corpus callosum adjusted for brain size in male and female subjects from childhood to adulthood. Behavioral Brain Research. 1994; 64:65-78.

Reser DH, Burman KJ, Richardson KE, Spitzer MW, Rosa MGP. Connections of the marmoset rostrotemporal auditory area: Express pathways for analysis of affective content in hearing. European Journal of Neuroscience. 2009; 30:578-592. [PubMed: 19663937]

Rilling JK, Insel T. Differential expansion of neural projection systems in primate brain evolution. NeuroReport. 1999; 10:1453-1459. [PubMed: 10380962] 
Ringo JL, Doty RW, Demeter S, Simard PY. Time is of the essence: A conjecture that hemispheric specialization arose from interhemispheric conduction delay. Cerebral Cortex. 1994; 4:331-343. [PubMed: 7950307]

Sanchez MM, Hearn EF, Do D, Rilling JK, Herndon JG. Differential rearing affects corpus callosum size and cognitive function of rhesus monkeys. Brain Research. 1998; 812:38-49. [PubMed: 9813233]

Sowell ER, Peterson BS, Thompson PM, Welcome SE, Henkenius AL, Toga AW. Mapping cortical change across the human life span. Nature Neuroscience. 2003; 6(3):309-315.10.1038/nn1008

Thompson PM, Giedd JN, Woods RP, MacDonald D, Evans AC, Toga AW. Growth patterns in the developing brain detected by continuum mechanical tensor maps. Nature Neuroscience. 2000; 404:190-193.

Tirapu-Ustarroz J, Luna-Lario P, Hernaez-Goni P, Garcia-Suescun I. Relation between white matter and cognitive functions. Revista de Neurologia. 2011; 52 (12):725-742. [PubMed: 21594858]

Wahl M, Lauterbach-Soon B, Hattingen E, Jung P, Singer O, Volz S, Klein JC, Steinmetz H, Ziemann U. Human motor corpus callosum: Topography, somatography, and link between microstructure and function. Journal of Neuroscience. 2007; 27:12132-12138. [PubMed: 17989279]

Wang PP, Doherty S, Hesselink JR, Bellugi U. Callosal morphology concurs with neurobehavioral and neuropathological findings in two neurodevelopmental disorders. Archives of Neurology. 1992; 49:407-411. [PubMed: 1532713]

Westerhausen R, Luders E, Specht K, Ofte SH, Toga AW, Thompson PM, Helland T, Hugdahl K. Structural and functional reorganization of the corpus callosum between the age of 6 and 8 years. Cerebral Cortex. 201010.1093/cercpr/bhq165

Witelson SF, Goldsmith CH. The relationship of hand preference to anatomy of the corpus callosum in men. Brain Research. 1991; 545 (1-2):175-182. [PubMed: 1860044]

Woodruff PW, McManus IC, David AS. Meta-analysis of corpus callosum size in schizophrenia. Journal of Neurology, Neurosurgery, and Psychiatry. 1995; 58:457-461.10.1136/jnnp.58.4.457 


\section{Highlights}

- The development of the corpus callosum (CC) in capuchin monkeys is described.

- High-resolution anatomical MRI scans were used to visualize and measure the CC.

- Total CC area and subdivision areas showed sustained linear or quadratic growth.

- Capuchins show similarities to humans with prolonged white matter development. 


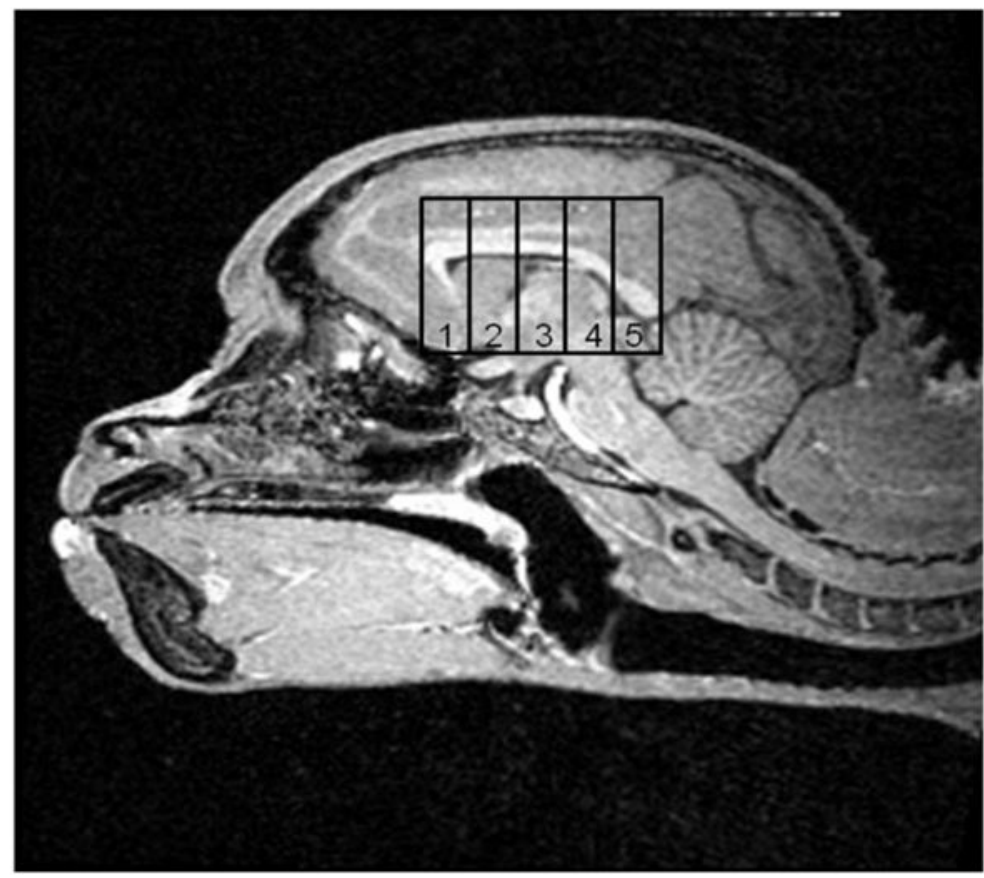

Figure 1.

Anatomical subdivision of the capuchin corpus callosum from MRI midsagittal view. The total midsagittal area was divided into five equally spaced subdivisions: $1=$ genu, $2=$ rostral midbody, 3 = medial midbody, 4 = caudal midbody, and $5=$ splenium. 
Figure 2a
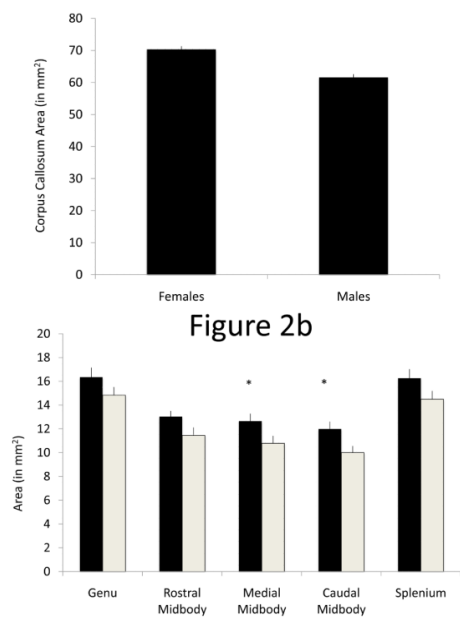

Figure 2.

Figures $2 \mathrm{a}$ and $2 \mathrm{~b}$. (a) Differences in total corpus callosum area in female and male capuchins $(M+S E)$. (b). Differences in area of corpus callosum subdivisions in female and male capuchins $(\mathrm{M}+\mathrm{SE})$. Females are represented by black bars; males represented by cream bars. 


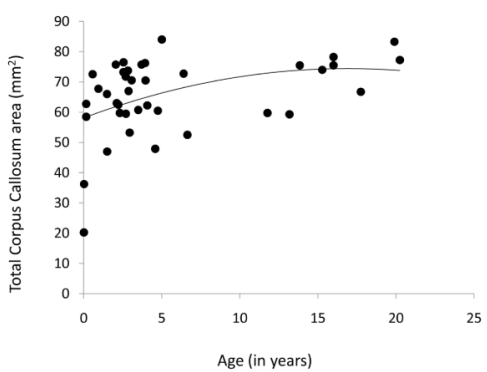

Figure 3.

Growth trajectory of the total midsagittal CC area (in $\mathrm{mm}^{2}$ ) in a sample of 37 capuchin monkeys ranging in age from 4 days -27 years. 
Figure 4a
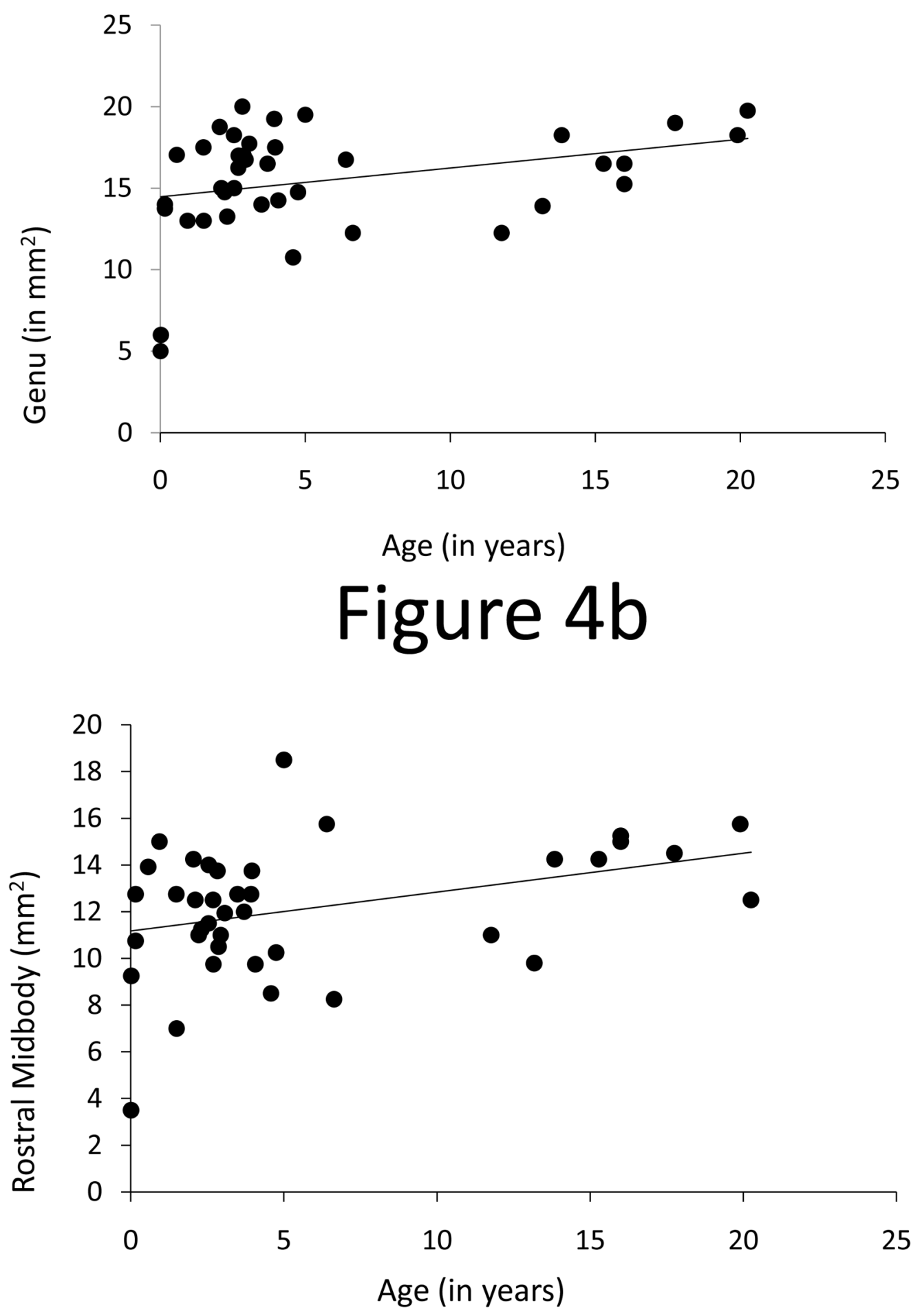

Neuroscience. Author manuscript; available in PMC 2013 January 27. 


\section{Figure 4c}
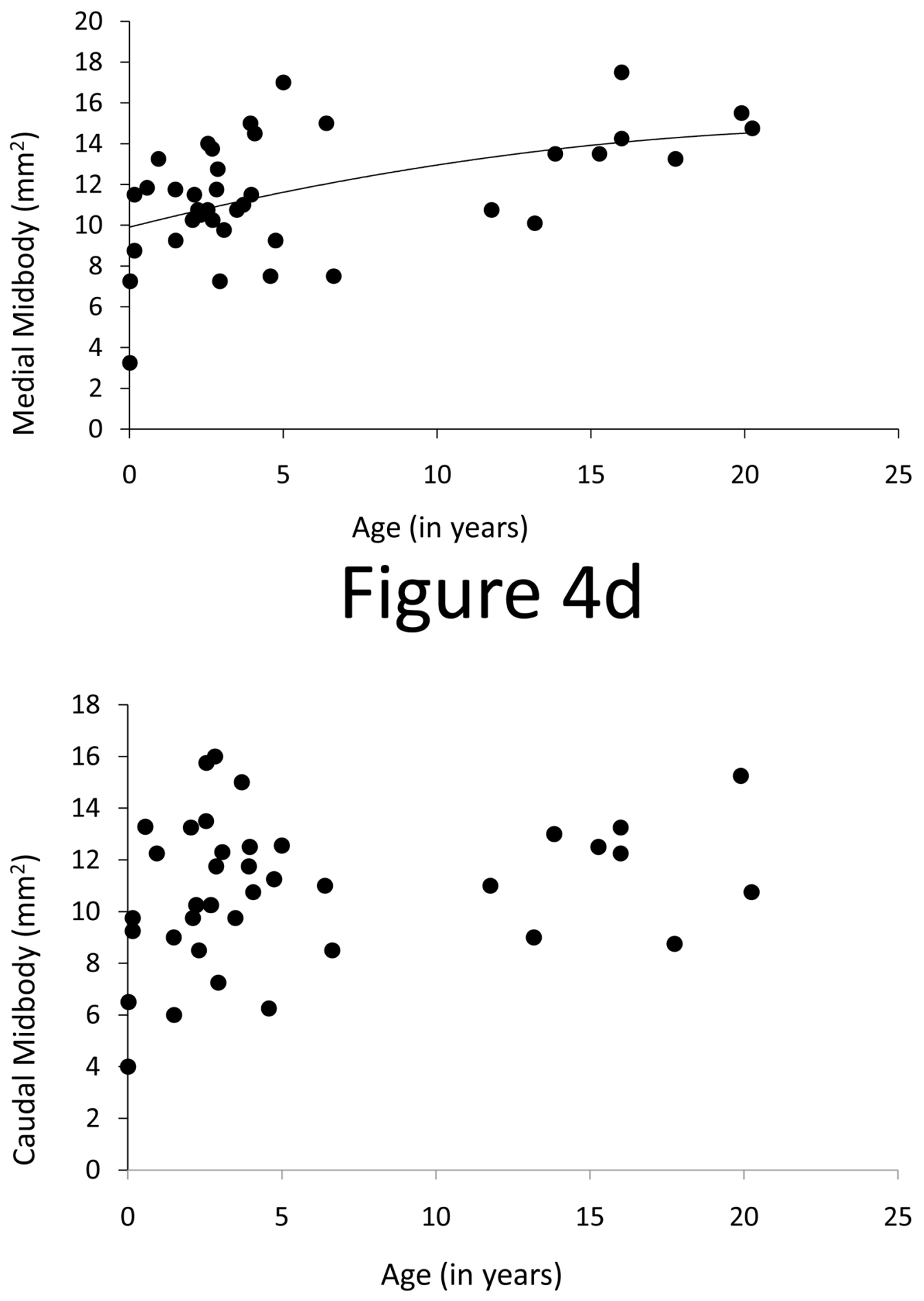

Neuroscience. Author manuscript; available in PMC 2013 January 27. 


\section{Figure 4e}

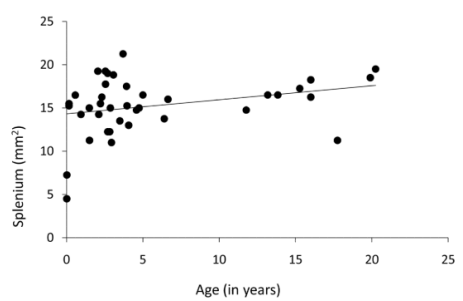

Figure 4.

Figures $4 \mathrm{a}-\mathrm{e}$. Growth trajectories of CC subdivisions in a sample of capuchin monkeys from 4 days - 27 years: (a) genu, (b) rostral midbody, (c) medial midbody, (d) caudal midbody, and (e) splenium. 